\title{
Mental health in times of the COVID-19 pandemic: Exploring the impact on well-being across the athlete-collegiate career
}

David Schary and Carolina Lundqvist

The self-archived postprint version of this journal article is available at Linköping University Institutional Repository (DiVA):

http:/ / urn.kb.se/ resolve?urn=urn:nbn:se:liu:diva- 176377

N.B.: When citing this work, cite the original publication.

Schary, D., Lundqvist, C., (2021), Mental health in times of the COVID-19 pandemic: Exploring the impact on well-being across the athlete-collegiate career, J ournal of Clinical Sport Psychology, 15(3), 249-267. https:// doi.org/ 10.1123/jcsp.2021-0041

Original publication available at:

https:// doi.org/ 10.1123/jcsp.2021-0041

Copyright: Human Kinetics

http:// www.humankinetics.com/ europe 
1

2

3

4

5

6

8

9

10

11

12

13

\section{Across the Athlete-Collegiate Career}

$$
\text { >>Accepted for publication }<<
$$

David P. Schary

Department of Physical Education, Sport and Human Performance, Winthrop University, U.S.A. Email: scharyd@winthrop.edu. ORCID: 0000-0002-6360-9599

Carolina Lundqvist

Department of Behavioral Sciences and Learning, Linköping University, Sweden.

Email: carolina.lundqvist@liu.se. ORCID: 0000-0001-6570-5480 


\section{Abstract}

15 In reaction to the COVID-19 pandemic, restrictive policies altered student-athletes' academic 16 and athletic life. Sparse research has investigated the pandemic's effect on student-athlete mental 17 health in terms of both negative (e.g., depression, anxiety) and positive (e.g., well-being, quality 18 of life) dimensions. This study explored the effect of the COVID-19 pandemic on well-being and 19 QOL among NCAA Division I student-athletes at different stages of their collegiate career.

20 Ninety-nine student-athletes $\left(M_{\text {age }}=19.7\right.$ years, $\left.S D=1.5\right)$ completed assessments on their mental 21 health. Regression analysis revealed experiences directly related to COVID-19 did not affect 22 general well-being or QOL, but anxiety, depression and significant insomnia did. Social well23 being was lower for student-athletes closer to graduation (e.g., juniors, seniors), independent of 24 reported anxiety and depression levels. These findings highlight the importance of psychosocial 25 support, particularly in times of crisis, and indicate that tailored support might be beneficial at 26 later stages of the collegiate years. 


\section{Introduction}

The unexpected COVID-19 pandemic significantly altered the operation of colleges and universities in the United States. To curtail the spread of the virus, state officials and college administrators implemented strict physical distancing policies and shifted to virtual instruction (Hartocollis, 2020). While necessary to limit the spread of the virus, these policies contributed to a dramatic rise in self-reported anxiety and depression among students (e.g., Hamaza et al., 2020;

34 Husky et al., 2020; Wang et al., 2020), as well as increased use of mental health and student support services across campuses (Lederer et al., 2021).

The long-term impact on mental health from these policies is still unknown; nonetheless, the immediate impact reveals worrisome trends. For example, among student-athletes, the National Collegiate Athletic Association (NCAA) found that rates of mental health concerns were up to two times higher than pre-pandemic rates (Johnson, 2021). This trend may be especially concerning because the pre-pandemic rates already reflected a high prevalence of illbeing and psychological distress among student-athletes. Davoren and Hwang (2014) reported that student-athletes' self-rated symptoms of depression varied between $21 \%$ - 28\% and selfrated symptoms of anxiety between $31 \%-38 \%$.

The pandemic increased mental health concerns that student-athletes have reported in studies for almost 10 years (Hainline, 2014). A predictor of mental health proposed in the literature is student-athletes’ levels of perceived stress (Davoren \& Hwang, 2014). As a group, student-athletes are at risk of experiencing a variety of stressors stemming from their academic and athletic responsibilities, such as role conflicts, academic and eligibility demands, physical and mental fatigue, and financial pressures (e.g., Cosh \& Tully, 2015; Simiyu, 2010). During the pandemic, Johnson (2021) reported that the most common stressors for student-athletes were 
51 limited access to their sport, academic pressures, COVID-19 health concerns, and financial 52 worries.

Despite the universal presence of these stressors among student-athletes, there is no

54 universal response to them. Instead, a variety of factors contribute and produce distinct

55 emotional and physiological responses and mental health outcomes. These factors include how

56 the stressors are perceived, individual learning history, genetic vulnerability and stress reactivity,

57 available coping resources, and access to environmental and social support (Engel, 1980;

58 Kemeny, 2003; Kimball \& Freysinger, 2003; Lundqvist, 2021).

\section{Well-Being and Quality of Life}

The World Health Organization (WHO; 2004) defines mental health as "a state of well-

61 being in which the individual realizes his or her abilities, can cope with normal stresses of life,

62 can work productively and fruitfully, and is able to make a contribution to his or her community”

63 (p. 12). Quality of Life (QOL) is commonly regarded in the psychological literature as the

64 subjective evaluation of general well-being (e.g., Green-Shortridge \& Odle-Dusseau, 2009). The

65 WHO (1999) defines QOL as “a broad ranging concept affected in a complex way by the

66 person's physical health, psychological state, personal beliefs, social relationships and their

67 relationship to salient features of their environment” (p. 3).

68 Despite the WHO’s emphasis on well-being in their definition of mental health and 69 functionality over disorder and dysfunction, most studies on athlete mental health have so far 70 investigated various negative elements of mental health (e.g., psychological distress) with sparse 71 attention directed towards positive elements (e.g., well-being, QOL; Kuettel \& Larsen, 2020;

72 Lundqvist, 2021). A one-sided focus on the negative indicators of mental health is problematic

73 considering that well-being, according to the WHO (2004) definition, is regarded as a desirable 
74

75

76

77

78

79

80

81

82

mental health status. In addition, the presence of psychological distress or mental illness does not automatically imply low levels of well-being or QOL (Uphill et al., 2016). For example, Van Slingerland and colleagues (2018) found that student-athletes had moderate to high levels of mental health functioning (i.e., higher levels of well-being) in the presence of negative mental health risk factors like numerous sources of stress, injury, and conflicting roles. By not assessing the positive elements of mental health, and the potentially protective nature of well-being and QOL, researchers may be at risk of overlooking how various psychosocial resources may help athletes stay functional and healthy, or even increase levels of resilience, despite the presence of stressors and/or other obstacles (e.g., Collins \& MacNamara, 2012; Lundqvist \& Sandin, 2014; Lundqvist, 2021; Sarkar et al., 2015).

Well-being as a scientific construct has a rich theoretical foundation within the broader field of psychology. Two distinct perspectives of well-being are suggested in the psychological literature: the hedonic and eudaimonic traditions (Lundqvist, 2011; Ryan \& Deci, 2001). The hedonic tradition uses the label subjective or emotional well-being and focuses on the emotionaloriented component of the construct (i.e., happiness/pleasure and life-satisfaction; e.g., Diener, 2009; Keyes, 2005). The eudaimonic perspective has two common conceptualizations: psychological and social well-being. Psychological well-being is the most widely used in the literature, examining one’s ability to thrive and act functionally amid life’s challenges (e.g., pursuing meaningful goals, developing as a person; Ryff, 2014). Social well-being indicates an individual's functioning and perceived flourishing in social life (Keyes, 1998). Although positive affect may be an outcome, the primary goal from a eudaimonic view is not subjective experiences of pleasure but personal growth, development, perceived meaningfulness in life 
(Huta \& Waterman, 2014). The three types of well-being are generally viewed as interrelated and individually contribute to a person’s mental health (Keyes et al., 2002).

\section{Within-Career Transitions}

Although relatively stable, well-being can change over time, especially during major life events or transitions. For traditional-aged students, attending and graduating college represents major transitions that can affect their levels of well-being (Bowman, 2010). Bewick et al. (2010) found that undergraduates had higher psychological well-being in their second semester than their first semester of college, suggesting that a transition into a new environment can temporarily reduce well-being. A college student's well-being may also be influenced by their level of academic readiness (Punia \& Malaviya, 2015), physical habits/behaviors (i.e., physical activity, tobacco use, sleep quality; Ridner et al., 2016), and the type of institution attended (Bowman, 2010).

Within sport and exercise psychology, the field of career transitions is a well-researched area, illuminating the common challenges faced by athletes transitioning out of sport and necessary support structures to make these transitions successful (e.g., Park et al., 2013; Stambulova \& Wylleman, 2014). There is however less research on within-career transitions among collegiate student-athletes, and particularly during the COVID-19 pandemic. Given the range of stressors student-athletes face in both their academic and athletic roles, within-career transitions need similar attention as end-of-career transitions. Noboa (2020) identified five common challenges student-athletes face as they transition through their collegiate career: (a) conflicting academic and athletic time commitment, (b) limited choice in academic major, (c) unavailability of study abroad programs and internships, (d) health problems and injuries, and (e) mental wellness concerns (e.g., low well-being, high psychological distress). Athletic 
119 departments have career and academic support to help address some of these concerns, and 120 social support and mentoring programs that are beneficial (Adams et al., 2015; Kelly \& Dixon, 121 2014). However, this support may not be sufficient to combat the broad spectrum of within122 career transition concerns student-athletes may face regarding mental health, particularly during 123 the unique challenges caused by a public health pandemic.

Stambulova’s (2003) Athletic Career Transition Model states that athletes need the right resources to effectively cope with a major transition, especially under stressful circumstances.

126 Before the COVID-19 pandemic, the transitory nature of college put students at an increased risk 127 for psychological distress (e.g., Baik et al., 2019; Graupensperger et al., 2020). Then given the 128 pandemic's unprecedented restrictive policies that altered academic and athletic life, many 129 student-athletes may not have been prepared to effectively cope with them. Due to the nascent 130 nature of the pandemic, there is little research on its impact on student-athlete well-being nor 131 mental health protective strategies. However, preliminary results indicate that teammate social 132 interactions (i.e., social support and connectedness) during the pandemic may have a protective 133 effect on mental health by increasing well-being (Graupensperger et al., 2020). Our aim was to address some of these gaps in the career transition literature regarding the 135 role of well-being, QOL, and within-career transitions among student-athletes. Specifically, the 136 purpose of this study was to explore the effect of the COVID-19 pandemic on well-being and 137 QOL during the Fall 2020 semester among NCAA Division I student-athletes at different stages 138 of the collegiate career (i.e., freshman, sophomore, junior, senior). Based on the previous 139 research described above, we make the following two hypotheses: (a) Negative experiences of 140 the COVID-19 pandemic (e.g., infection, quarantine), depression, anxiety or worry, and 141 insomnia will negatively affect student-athlete well-being and QOL and (b) similar to previous 
142 findings by Bewick et al. (2010), well-being and QOL will be lower for early-stage student143 athletes (freshman, sophomores) compared to later-stage student-athletes (juniors, seniors).

\section{Method}

145 Participants

A total of 99 student-athletes $\left(M_{\text {age }}=19.7\right.$ years, $\left.S D=1.5\right)$ from two NCAA Division I

147 universities in the United States participated in this study. Participants were required to be at 148 least 18 years old and current student-athletes at the time of the study. As displayed in Table 1, 149 participants were predominantly male $(n=65)$ and Caucasian $(n=77)$, most had a full $(n=14)$ 150 or partial athletic scholarship $(n=56)$. Academic levels were relatively evenly distributed among participants; Freshman: $n=29$, Sophomores: $n=21$, Juniors: $n=24$, Seniors: $n=18$, other

152 academic levels: $n=7$ (i.e., $5^{\text {th }}$ year senior or graduate student). Both individual and team sports 153 were represented in the sample, lacrosse displayed the highest number of participants $(n=34)$.

154 Most participants had been playing their sport for eight or more years $(n=72)$. Seventeen 155 student-athletes were not included in the study because they did not complete the assessments,

156 but they did not significantly differ from those included in the study on sociodemographic 157 characteristics.

158 COVID-19

Every participant reported experiencing at least one negative consequence associated with COVID-19. Six participants reported they had tested positive for COVID-19. Almost all

161 participants $(n=85)$ responded they knew at least one other person, within or outside of 162 athletics, who had been diagnosed with the infection. Moreover, 25 participants knew at least one person who had serious complications or died as a result. A total of 48 participants had also been quarantined for 14 days at least once after exposure to another COVID-19 positive person. 


\section{Measures}

\section{Mental Health Continuum - Short Form (MHC-SF)}

The MHC-SF (Keyes et al., 2008) is a 14-item questionnaire assessing subjective (3 items), psychological (6 items), and social well-being (5 items) based on Ryff's (1989) and Keyes’ (1998) well-being models. Respondents rate their responses on a 6-point Likert scale, ranging from 0 (never) to 5 (every day) which are summed to an overall well-being score (range: 0 - 70). In addition, subscale scores are calculated for subjective well-being (range: 0-15), psychological well-being (range: 0-30) and social well-being (range 0-25). Higher scores represent higher wellbeing. Previous studies have shown the MCH-SF to have acceptable internal reliability (all subscales $\alpha \geq .80$ ) and validity (e.g., Lamers et al., 2011). Internal reliability was acceptable for all subscales in this current study (overall well-being: $\alpha=.92$; subjective well-being: $\alpha=.95$; psychological well-being: $\alpha=.83$; social well-being: $\alpha=.84$ ).

\section{Brunnsviken Brief Quality of Life Scale (BBQ)}

The BBQ (Lindner et al., 2016) is a 12-item questionnaire assessing the subjective experience of QOL using a 5-point Likert scale, ranging from 0 (do not agree at all) to 4 (agree completely). The 12 items cover six life areas: leisure, view on life, creativity, learning, friends and friendship, and self-view. Each life area has two items measuring both satisfaction and the importance of each life area are measured. The BBQ total score is computed by multiplying the satisfaction and importance items for each life area and summing the six products. Total scores range from 0 to 96, higher scores indicate a more positive assessment of QOL. In previous research, the BBQ has shown good internal reliability $(\alpha=.76)$ with strong concurrent and convergent validity (Lindner et al., 2016). In the current study, internal reliability was $\alpha=.83$.

\section{Hospital Anxiety and Depression Scale (HADS)}


The HADS (Zigmond \& Snaith, 1983) is a 14-item questionnaire that screens for symptoms of anxiety (7 items) and depression (7 items) in the previous week. The anxiety and depression subscales use a 4-point Likert scale, ranging from 0 (e.g., not at all) to 3 (e.g., Most of the time), totals range from 0 to 21. Higher scores indicate greater psychological distress; scores between 8-10 are regarded as borderline (i.e., a score between subclinical and clinical which might indicate a clinical condition of anxiety or depression) and scores of 11 or above is regarded as an indication that the person likely displays clinically relevant depression or anxiety (Zigmond \& Snaith, 1983). Borderline scores (8-10) are labeled throughout this study as subclinical anxiety/depression and scores of 11 or higher as clinical anxiety/depression. Reviewing previous research, Herrmann (1997) found strong internal reliability for both subscales (anxiety $\alpha=.90-$ 0.93; depression $\alpha=.81-.90$ ), as well as discriminant and concurrent validity. In the current study, internal reliability was $\alpha=.76$ for depression and $\alpha=.82$ for anxiety.

\section{Penn State Worry Questionnaire (PSWQ)}

The PSWQ (Meyer et al., 1990) assesses an individual's worry or the cognitive component of anxiety. It uses 16 items that are measured on a 5-point Likert scale, ranging from 0 (not at all like me) to 4 (very typical of me). The overall score is the sum of all the items, ranging from 0 to 64, higher scores represent higher levels of worry. Previous research has shown high levels of internal reliability (e.g., $\alpha \geq .90$ ) and strong validity (Meyer et al., 1990). In the current study, internal reliability was $\alpha=.94$.

\section{Sleep Disorders Questionnaire (SDQ)}

The SDQ (Alberta Medical Association, 2015) screens for insomnia using 16 items covering 5 diagnostic subscales: insomnia (5 items), psychiatric disorders (4 items), circadian rhythm disorder (1 item), movement disorder (2 items), and parasomnias (1 item). This study only used 
211 the insomnia subscale. Respondents rate their answer on a 5-point Likert scale, ranging from 1

212 (Never) to 5 (Always). The SDQ is primarily used as a clinical screening tool whereby each item

213 represents a possible symptom of insomnia. As a result, scoring a 3, 4, or 5 on any one insomnia

214 item infers that the individual likely suffers from insomnia. The individual likely suffers from

215 significant insomnia that impairs daily activity if he or she scores a 3, 4, or 5 on any two

216 insomnia items. In the current study, the internal reliability was $\alpha=.85$.

217 Procedures

Following standard procedures for ethical approval in the United States, the institutional 219 review board from the first author's university approved this study. Convenience sampling was used to collect data, head coaches and team captains were contacted via email about the study, then they were asked to distribute the description of the study with a link to the questionnaire to

222 their teams via email or text message. Before the participants completed the questionnaires, they

223 all received information about the study and provided their informed consent. After providing 224 their consent, the participants completed the questionnaire which consisted of demographic 225 questions, COVID-19 experience questions, and all the measures described in the previous 226 section. The information, informed consent, and questionnaire were distributed online using 227 Qualtrics software (Qualtrics, Provo, UT).

228 Data Analysis

For descriptive statistics and study variables, means were calculated for continuous

230 variables and proportions for categorical variables. To quantify a participant's COVID-19

231 negative experiences, first the number of negative experiences with a yes or no answer were

232 summed (i.e., personal diagnosis, quarantined, teammate/coach diagnosis, family/friend 233 diagnosis, knew someone with a serious complication). Each question answered with a "yes" 
234 was coded 1 and "no" was coded 0 . This total was then added to the number of times an

235

236

238 individual was quarantined (range: 0 - 5) to get a final COVID-19 experience score. The average number of COVID-19 experiences for each participant was $2.83(S D=1.89)$.

Multiple linear regression was used to measure the effect of a participant's mental health variables (i.e., anxiety, depression, worry, insomnia) and COVID-19 experience on well-being and QOL. For all analyses, academic standing was included as a control, it was the only demographic variable significantly related to the dependent variables. Results include R-squared values, beta coefficients, p-values, and 95\% confidence intervals. Statistical significance was established at $p<0.05$. All analyses were performed in $\mathrm{R}$ (version 4.0.3).

Results

Means and standard deviations for all continuous variables are shown in Table 2. On average, participants scored a $47.67(S D=12.14)$ of a possible 70 for total well-being and 57.97 ( $S D=19.17$ ) of a possible 96 for QOL. In general, all well-being (total and sub-categories) and QOL scores were lower for participants in the later stages of their college careers. There was no clear pattern for COVID-19 and worry scores, both held relatively constant across all groups. The descriptive statistics for all categorical variables are also shown in Table 2. Most participants did not report suffering from depression symptoms $(n=81)$. However, more than half of the participants reported experiencing anxiety symptoms, classified as either subclinical ( $n=21)$ or clinical $(n=36)$. Most participants showed symptoms of insomnia, with most suffering from significant insomnia. Like well-being and QOL, depression and anxiety were lower for participants in the later stages of their college careers. Insomnia held relatively constant with a small decline in sophomore year.

\section{Hypothesis 1}


As seen in Tables 3 and 4, the negative COVID-19 experience score did not significantly

258 affect reported overall well-being or QOL but significantly affected the sub-dimension of

259 psychological well-being $(B=-0.58,95 \%$ CI [-1.03, -0.13]). The participants’ self-reported

260 depression and anxiety scores did significantly affect total well-being: subclinical depression (B

$261=-8.51,95 \%$ CI [-13.93, -3.18]), subclinical anxiety $(B=-7.26,95 \%$ CI $[-12.24,-2.29])$, and

262 clinical anxiety $(B=-12.36,95 \%$ CI $[-18.34,-6.38])$. Similar results were found for the

263 subdimensions of subjective, psychological, and social well-being (Table 4). Subclinical $(B=$ -

264 13.32, 95\% CI [-22.5, -4.14]), clinical anxiety $(B=-18.64,95 \%$ CI $[-29.65,-7.59])$ and worry $(B$

$265=0.42,95 \%$ CI $[0.08,0.75])$ significantly predicted QOL. Insomnia did not significantly impact

266 well-being (total or sub-categories) or QOL, but the analyses showed that significant insomnia

267 had a statistically significant negative effect on psychological well-being ( $B=-2.82,95 \%$ CI [-

$2685.68,0.04])$ and QOL $(B=-15.34,95 \%$ CI $[-26.29,-4.39])$ when compared to those athletes who

269 did not report severe insomnia. Although some of the relationships between the variables were

270 unexpected, the total variance explained for all models was significant, ranging from 45\% (QOL)

271 to 58\% (total well-being).

272 Hypothesis 2

273

The later-stage student-athletes significantly differed from the reference group

274 (freshmen) for overall well-being, social well-being, and QOL (see Tables 3 and 4). For well-

275 being, juniors, seniors, and others (i.e., $5^{\text {th }}$ year senior or graduate students) reported lower scores

276 than freshman. For QOL, only juniors and others had significantly lower scores than freshman.

277 Sophomores did not significantly differ from freshman in reported well-being and QOL. 


\section{Discussion}

The purpose of this study was to explore the effects of the COVID-19 pandemic on wellbeing and QOL among student-athletes at different stages of the collegiate career. The results only partially supported our two hypotheses. Our first hypothesis predicted that the participant's experiences from the COVID-19 pandemic would negatively affect student-athlete well-being and QOL. The athletes' scores indicated that overall well-being and QOL were negatively affected; however, for our sample, it was not due to factors directly related to COVID-19 (e.g., testing positive, being quarantined, knowing someone with serious complications). Instead, the most consistent predictors of decreased well-being and QOL were self-reported symptoms of depression, anxiety, and significant insomnia.

These results support the idea of the importance of mental health awareness and the availability of psychosocial support systems also for athletes outside of the elite and professional levels, like student-athletes, in challenging periods such as pandemics (e.g., Lundqvist, 2021; Stambulova et al., 2020). As a population, student-athletes are generally in a sensitive development phase of their lives and sports careers where increased stress levels may be reported (e.g., Stambulova \& Wylleman, 2015; Wylleman et al., 2013). Previous studies performed during the COVID-19 pandemic indicated that student-athletes may be particularly vulnerable to experience increased mental distress, specifically depression and anxiety, if availability to ordinary training facilities and psychosocial resources to manage stress and anxiety are insufficient (e.g., Bullard, 2020; Graupensperger et a., 2020; Pons et al., 2020). From both mental health and sports performance perspective, it may therefore be beneficial to preemptively institute psychosocial interventions tailored to collegiate student-athletes with content adaptable to mental health awareness and crisis management. This would give most student-athletes the 
necessary skills to remain functional during unexpected stressful situations and provide a foundation for those that may need professional treatment.

Our second hypothesis predicted that well-being and QOL would be lower for early-stage student-athletes compared to later-stage student-athletes. The results found in this study revealed nevertheless the opposite pattern. In our sample, student-athletes in the later stages of their college years (i.e., juniors, seniors, graduate students) reported decreased levels of overall wellbeing and QOL compared to freshman. Particularly noteworthy was the unexpected decrease in social well-being among the older student-athletes. The unprecedented scale of the COVID-19 pandemic likely amplified struggles to many student-athletes and may have exposed the deficiencies in the student-athlete support system. The positive role of social support from athletic trainers, coaches, teammates, and other significant persons when athletes confront various obstacles is well-known in the research literature (e.g., Clement \& Shannon, 2011; Rees et al., 2010).

In addition, social integration and social contribution are two components of social wellbeing that further may help explain our unanticipated finding. According to Keyes (1998), social integration is the extent to which people feel they belong to certain communities or social groups; whereas social contribution is the evaluation of one's social value or the belief that one is a contributing member of society (Keyes, 1998). The policies put into place to limit the spread of COVID-19 may have weakened the feelings of social integration and contribution because teams could not practice or compete, limiting how much a student-athlete could feel like an active member and contributor to the team. While all student-athletes in our sample faced the same restrictions, upperclassmen may have experienced more social distress as a result because of their proximity to graduation. For most student-athletes, graduation is a major life transition that 
324 signifies the termination of their competitive athletic career. Typically, social support is a useful 325 coping resource that helps student-athletes when faced with these types of major transitions 326 (Brown et al., 2015). Our finding may therefore indicate that the perceived social security of 327 having years left in college and/or athletic eligibility, and the feelings of social integration and 328 contribution this provides, could potentially act as a protective effect for social well-being during 329 the pandemic period. Although presently somewhat speculative based on available data, 330 researchers are encouraged to investigate this hypothesis further, as well as search for feasible 331 strategies to help student-athletes proactively protect their social well-being as graduation 332 approaches.

A relatively large proportion of research has been conducted on career transitions between 334 different career stages or phases of life (Stambulova \& Roy, 2019). However, fewer studies have 335 directly focused on within career transitions during college, and particularly related to challenges 336 and potential mental health effects associated with the COVID-19 pandemic. Our results indicate 337 that psychosocial needs may change from freshman year to later college years; thus, tailored 338 psychosocial support may be needed to meet these changes for maximum efficiency. Future 339 research should explore what needs of preventive support to maintain well-being and QOL that student-athletes express during different phases of their college years, specifically stressful and 341 crisis-like situations such as pandemics. The adoption of a biopsychosocial perspective (e.g., 342 Engel, 1980; Suls \& Rothman, 2004) can be a valuable research approach because it allows for 343 the investigation of various mediating factors that can help explain different relationships that 344 may exist between stress exposure and mental health outcomes among student-athletes.

345 Moreover, longitudinal research designs are necessary to evaluate acute responses (i.e., various 346 mental health symptoms) to these types of psychological challenges. Particularly focusing on the 
347 long-term effects on a student-athlete's mental health (e.g., clinical issues) and development 348 (e.g., learning experiences, maturation, resilience).

\section{Limitations \& Future Directions}

Although our study yielded several interesting findings, it is not without limitations. Importantly, our results are based on cross-sectional data which only captures one point in time. The adoption of longitudinal and replication designs would enable possibilities to also determine causal factors that may affect well-being and QOL across the collegiate career. Including assessments of plausible mediating biopsychosocial factors could, in addition, increase our understanding of various mechanisms behind student-athletes’ different responses to the COVID-19 pandemic. For example, why some suffered negative outcomes (e.g., psychological distress) while others seemed unaffected. Various levels of resilience and/or the availability of proper social support among student-athletes could plausibly be mediating variables of value to further explore in research.

Although our study included a variety of sports, the modest sample size and convenience sampling procedure limit the generalizability of the results to a larger population of studentathletes. Most of our participants were male and Caucasian; as a result, their experiences during the pandemic may differ from minority and underrepresented groups. Similarly, participants in our study were selected from two NCAA Division I institutions in the United States. When interpreting the results, readers should consider that student-athletes at Division II or III may face alternative challenges than were found in this study. In addition, policies aimed at limiting the spread of COVID-19 varied by region, whereby the stressors faced in other parts of the United States, or other countries, could be different from those in our study. Participants may not have been negatively affected by their COVID-19 experiences, particularly being quarantined. In 
370 addition, due to the structure of the COVID-19 assessment, we did not capture the level of

371 severity for each experience, but it likely differed among participants. Moreover, whereas the

372 study's quantitative approach allowed for the examination of general trends of well-being and

373 QOL across the collegiate career, it also limited the possibility to obtain a deeper understanding

374 of student-athletes' individual experiences and any contextual variations that may have affected

375 their well-being and QOL during the pandemic. We, therefore, recommend that future

376 researchers adopt qualitative methods to explore student-athletes’ idiosyncratic experiences of

377 the pandemic.

378 Clinical Implications

This study has several clinical implications highlighting the importance of an extended 380 psychosocial support system around student-athletes particularly in times of crisis, such as global pandemics or severe and career-ending injuries. The results indicated that although the COVID-

38219 pandemic induced a disruption to academic and athletic life, well-being and QOL may be maintained via social factors. It is well-known from the clinical literature (e.g., Hammen, 2015;

Martell et al., 2010) that significant and life-changing stressors confronted may pose an increased risk for the development of depression and anxiety among persons. Early preventive support with low-intensity interventions may be highly beneficial to help avoid clinical issues to

387 develop and to support various behaviors that are related to increased well-being and QOL (cf.

388 Lundqvist, 2020). This can also include the use of digital technology (i.e., apps, videos, online 389 sessions) that provide athletes with the opportunity to stay connected, learn new skills, and 390 receive appropriate levels of support, especially in times when social distance is necessary 391 (Lundqvist et al., in press). Of equal importance is easy access to clinical and sports-adapted psychological support for those athletes who develop more serious clinical problems in need of 
treatment. Early intervention, when mental health concerns first surface, is usually beneficial for the treatment prognosis (e.g., Lundqvist, 2020; Purcell et al., 2019). Athletes' help-seeking behavior should therefore be both accepted in the sports culture and encouraged by significant people in the environment (e.g., coaches, teachers), and the sports system in general.

Arguably, support systems around student-athletes should be flexible and include staff that is qualified enough to meet a great number of mental health, sports performance, and academic needs. Coaches and academic instructors who regularly are in close contact with studentathletes' can act as a general supportive resource. This can range from informal support like weekly check-ins with student-athletes to formal programming or team meetings that cover topics like stress management. All support staff should ensure that they are knowledgeable about common psychological reactions to stress, how various needs might be expressed in times of crisis and should be aware when symptoms require referral to qualified clinical support. A formalized referral process with a university's mental health services can also help expedient the referral process.

Finally, to ensure high levels of well-being and QOL among student-athletes across their collegiate career, our results suggest that tailored psychosocial support might be beneficial at later stages of the collegiate years that extend beyond career readiness. This can include evidence-based programming and/or workshops that address topics pertinent to improving wellbeing and QOL. For example, during the COVID-19 pandemic, successful programming for elite athletes has included topics like resilience, adaptability, personal growth/development, and developing positive relationships (Lundqvist et al., in press). Since the needs will vary and can change over time, we recommend athletic department administrator's and support personnel regularly survey their student-athletes for the most appropriate types of support. 


\section{References}

417

418

419

420

421

422

423

424

425

426

427

428

429

430

431

432

433

434

435

436

437

438

439

Adams, C., Coffee, P., \& Lavallee, D. (2015). Athletes’ perceptions about the availability of social support during within-career transitions. Sport and Exercise Psychology Review, 11(2), 37-48.

Alberta Medical Association. (2015). Sleep Disorders Questionnaire. https://actt.albertadoctors.org/CPGs/Pages/Adult-Insomnia.aspx

Bewick, B., Koutsopoulou, G., Miles, J., Slaa, E., \& Barkham, M. (2010). Changes in undergraduate students' psychological well-being as they progress through university. Studies in Higher Education, 35(6), 633-645.

https://doi.org/10.1080/03075070903216643

Bowman, N. A. (2010). The development of psychological well-being among first-Year college students. Journal of College Student Development, 51(2), 180-200. https://doi.org/10.1353/csd.0.0118

Brown, D. J., Fletcher, D., Henry, I., Borrie, A., Emmett, J., Buzza, A., \& Wombwell, S. (2015). A British university case study of the transitional experiences of student-athletes. Psychology of Sport and Exercise, 21, 78-90. https://doi.org/10.1016/j.psychsport.2015.04.002

Bullard, J. B. (2020). The impact of COVID-19 on the well-being of division III student-athletes. The Sport Journal. Available at: https://thesportjournal.org/article/the-impact-of-covid19-on-the-well-being-of-division-iii-student-athletes/

Clement, D., \& Shannon, W. R. (2011). Injured athletes’ perceptions about social support. Journal of Sport Rehabilitation, 20(4), 457-470. https://doi.org/10.1123/jsr.20.4.457

Collins, D., and MacNamara, A. (2012). The rocky road to the top: Why talent needs trauma. Sports Med. 42, 907-914. http://doi.org/10.1007/BF03262302 
440

441

442

443

444

445

446

447

448

449

450

451

452

453

454

455

456

457

458

459

460

461

462

Cosh, S., \& Tully, P. J. (2015). Stressors, coping, and support mechanisms for student athletes combining elite sport and tertiary education: Implications for practice. The Sport Psychologist, 29(2), 120-133. https://doi.org/10.1123/tsp.2014-0102

Davoren, A. K., \& Hwang, S. (2014). Depression and anxiety prevalence in student-athletes. In G. T. Brown (Ed.), Mind, body and sport: Understanding and supporting student-athlete mental wellness (pp. 38-39). National Collegiate Athletic Association.

Diener, E. (2009). Subjective well-being. In E. Diener (Ed.), Social Indicators of Research Series. The science of well-being (Vol. 37, pp. 11-58). Springer Science Business Media

Engel, G. L. (1980). The clinical application of the biopsychosocial model. American Journal of Psychiatry, 137, 535-544. https//doi.org/10.1176/ajp.137.5.535

Graupensperger, S., Benson, A. J., Kilmer, J. R., \& Evans, M. R. (2020). Social (un)distancing: Teammate interactions, athletic identity, and mental health of student-athletes during the COVID-19 pandemic. Journal of Adoescent Health, 67, 662-670. https://doi.org/10.1016/j.jadohealth.2020.08.001

Green-Shortridge, T. M., \& Odle-Dusseau, H. N. (2009). Quality of life. In S. J. Lopez (Ed.), The encyclopedia of positive psychology (pp. 817-821). John Wiley \& Sons.

Hainline, B. (2014). Introduction. In G. T. Brown (Ed.), Mind, body and sport: Understanding and supporting student-athlete mental wellness. National Collegiate Athletic Association.

Hamaza, C. A., Ewing, L., Heath, N. L., \& Goldstein, A. L. (2020). When social isolation is nothing new: A longitudinal study psychological distress during COVID-19 among university students with and without preexisting mental health concerns. Canadian Psychology/Psychologie Canadienne, Advance online publication. https://doi.org/10.1037/cap0000255 
463

464

465

466

467

468

469

470

471

472

473

474

475

476

477

478

479

480

481

482

483

484

485

486

Hammen, C.L. (2015). Stress and depression: Old questions, new approaches. Current Opinion in Psychology, 4, 80-85. https://doi.org/10.1016/j.copsyc.2014.12.024

Hartocollis, A. (2020, March 11). 'An eviction notice’: Chaos after colleges tell students to stay away. The New York Times. https://www.nytimes.com/2020/03/11/us/colleges-cancelclasses-coronavirus.html

Herrmann, C. (1997). International experiences with the Hospisal Anxiety and Depression Scale-A review of validation data and clinical results. Journal of Psychosomatic Research, 42(1), 17-41. https://doi.org/10.1016/S0022-3999(96)00216-4

Husky, M., Kovess-Masfety, V., \& Swendsen, J. D. (2020). Stress and anxiety among university students in France during Covid-19 mandatory confinement. Comprehensive Psychology, 102, 152191. https://doi.org/10.1016/j.comppsych.2020.152191

Huta, V., \& Waterman, A. S. (2014). Eudaimonia and its distinction from hedonia: Developing a classification and terminology for understanding conceptual and operational definitions. Journal of Happiness Studies, 15, 1425-1456. https//www.doi.org/10.1007/s10902-0139485-0

Johnson, G. (2021, February 16). Pandemic continues to impact student-athlete mental health. National Collegiate Athletic Association. https://www.ncaa.org/about/resources/mediacenter/news/pandemic-continues-impact-student-athlete-mental-health

Kelly, D. D., \& Dixon, M. A. (2014). Successfully navigating life transitions among African American male student-athletes: A review and examination of constellation mentoring as a promising strategy. Journal of Sport Management, 28(5), 498-514. https://doi.org/10.1123/jsm.2012-0320

Kemeny, M. E. (2003). The psychobiology of stress. Current Directions in Psychological Science, 12(4), 124-129. https://doi.org/10.1111/1467-8721.01246 
487 488 489 490 491 492 493 494 495 496 497 498 499 500 501 502 503 504 505 506 507 508 509 510

Keyes, C. L. M. (1998). Social well-being. Social Psychology Quarterly, 61(2), 121-140. https://doi.org/10.2307/2787065

Keyes, C. L. M. (2005). Mental illness and/or mental health? Investigating axioms of the complete state model of health. Journal of Consulting and Clinical Psychology, 73, 539_ 548. https//doi.org/10.1037/0022-006X.73.3.539

Keyes, C. L. M., Shmotkin, D., \& Ryff, C. D. (2002). Optimizing well-being: The empirical encounter of two traditions. Journal of Personality and Social Psychology, 82(6), 10071022. https://doi.org/10.1037/0022-3514.82.6.1007

Keyes, C. L. M., Wissing, M., Potgieter, J. P., Kruger, A., \& van Rooy, S. (2008). Evaluation of the mental health continuum-short form (MHC-SF) in Setswana-speaking South Africans. Clinical Psychology \& Psychotherapy, 15(3), 181-192. http:// doi.org/10.1002/cpp.572

Kimball, A., \& Freysinger, V. J. (2003). Leisure, stress, and coping: The sport participation of collegiate student-athletes. Leisure Sciences, 25(2-3), 115-141. https://doi.org/10.1080/01490400306569

Kuettel, A., \& Larsen, C. H. (2020). Risk and protective factors for mental health in elite athletes: A scoping review. International Review of Sport and Exercise Psychology, 13, 231-265. https://doi.org/10.1080/1750984X.2019.1689574

Lamers, S. M. A., Westerhof, G. J., Bohlmeijer, E. T., ten Klooster, P. M., \& Keyes, C. L. M. (2011). Evaluating the psychometric properties of the Mental Health Coninuum-Short Form (MHC-SF). Journal of Clinical Psychology, 67(1), 99-110. http://doi.org/10.1002/jcl p.20741

Lederer, A., Hoban, M. T., Lipson, S. K., Zhou, S., \& Eisenberg, D. (2021). More Than Inconvenienced: The Unique Needs of U.S. College Students During the COVID-19 
Pandemic. Health Educator \& Behavior, 48(1), Advance online publication. https://doi.org/10.1177/1090198120969372

Lindner, P., Frykheden, O., Forsström, D., Andersson, E., Ljótsson, B., Andersson, G., \& Carlbring, P. (2016). The Brunnsviken brief quality of life scale (BBQ): Development and psychometric evaluation. Cognitive Behaviour Therapy, 45(3), 182-195. https://doi.org/10.1080/16506073.2016.1143526

Lundqvist, C. (2011). Well-being in competitive sports—-The feel-good factor? A review of conceptual considerations of well-being. International Review of Sport and Exercise Psychology, 4(2), 109-127. https://doi.org/10.1080/1750984X.2011.584067

Lundqvist, C. (2021). Well-being and quality of life. In R. Arnold \& D. Fletcher (Eds.), Stress, well-being and performance in sport (pp. 131-147). Routledge.

Lundqvist, C., \& Sandin, F. (2014). Well-being in elite sport: Dimensions of hedonic and eudaimonic well-being among elite orienteers. The Sport Psychologist, 28, 245-254. https://doi.org/10.1123/tsp.2013-0024

Lundqvist, C., Macdougall, H., Noguchi, Y., Malherbe, A., \& Abejean, F. (in press). When COVID_19 struck the world and elite sport: Psychological challenges and support provision in five countries during the first phase of the pandemic. Journal of Sport Psychology in Action. https://doi.org/10.1080/21520704.2021.1931594

Martell, C.R., Dimidjian, S., Herman-Dunn, R., Lewinsohn, P.M., \& Herman-Dunn, R. (2010). Behavioral activation for depression: A clinician’s guide. New York: Guilford Publications. 
532 Meyer, T. J., Miller, M. L., Metzger, R. L., \& Borkovec, T. D. (1990). Development and

533

534

535

536 validation of the Penn State Worry Questionnaire. Behavior Research and Therapy, 28(6), 487-495. https://doi.org/10.1016/0005-7967(90)90135-6

Noboa, L. (2020). The transition through higher education: An exploration of challenges, barriers, and support services for student-athletes [Dissertation, University of Central Florida]. Electronic Theses and Dissertations, 2020-. https://stars.library.ucf.edu/etd2020/258

Park, S., Lavallee, D., \& Tod, D. (2013). Athletes’ career transition out of sport: A systematic review. International Review of Sport and Exercise Psychology, 6(1), 22-53. https://doi.org/10.1080/1750984X.2012.687053

Pons, J., Ramis, Y., Alcaraz, S., Jordana, A., Borrueco, M., \& Torregrossa, M. (2020). Where did all the sport go? Negative impact of COVID-19 lockdown on life-spheres and mental health of Spanish young athletes. Frontiers in Psychology, 11, 611872. http://doi.org/10.3389/fpsyg.2020.611872

Punia, N., \& Malaviya, R. (2015). Psychological Well Being of First Year College Students. Indian Journal of Educational Studies: An Interdisciplinary Journarl, 2(1), 60-68. https://ccemohali.org/img/Ch\%208\%20Punia\%20and\%20Malviya.pdf

Purcell, R., Gwyther, K., \& Rice, S.M. (2019). Mental health in elite athletes: Increased awareness requires an early intervention framework to respond to athlete needs. Sports Medicine Open, 5(1), 46. https://doi.org/10.1186/s40798-019-0220-1Rees, T., Mitchell, I., Evans, L., \& Hardy, L. (2010). Stressors, social support and psychological responses to sport injury in high- and low-performance standard participants. Psychology of Sport and Exercise, 11(6), 505-515. https://doi.org/10.1016/j.psychsport.2010.07.002 
Ridner, S. L., Newton, K. S., Staten, R. R., Crawford, T. N., \& Hall, L. A. (2016). Predictors of well-being among college students. Journal of American College Health, 64(2), 116-124. https://doi.org/10.1080/07448481.2015.1085057

Ryan, R. M., \& Deci, E. L. (2001). On happiness and human potentials: A review of research on hedonic and eudaimonic well-being. Annual Review of Psychology, 52, 141-166. https://doi.org/10.1146/annurev.psych.52.1.141

Ryff, C. D. (1989). Happiness is everything, or is it? Explorations on the meaning of psychological wellbeing. Journal of Personality and Social Psychology, 57(6), 10691081. https://doi.org/10.1037/0022-3514.57.6.1069

Ryff, C. D. (2014). Psychological well-being revisited: Advances in the science and practice of eudaimonia. Psychotherapy and Psychosomatics, 83, 10-28. https://doi.org/10.1159/000353263

Sarkar, M., Fletcher, D., and Brown, D.J. (2015). What doesn’t kill me...: Adversity-related experiences are vital in the development of superior Olympic performance. Journal of Science and Medicine in Sport, 18(4), 475-479. http://doi.org 10.1016/j.jsams.2014.06.010

Simiyu, N. W. W. (2010). Individual and institutional challenges facing student athletes on U.S. college campuses. Journal of Physical Education and Sports Management, 1(2), 16-24. https://doi.org/10.5897/JPESM.9000012

Suls, J., \& Rothman, A. (2004). Evolution of the biopsychosocial model: Prospects and challenges for health psychology. Health Psychology, 23, 119-125. https://doi.org/10.1037/0278-6133.23.2.119

Stambulova, N. B. (2003). Working with athletes in career transitions. In S. Hanton \& D. Mellalieu (Eds.). Professional practice in sport psychology: A review. Routledge. 
578 Stambulova, N. B., \& Wylleman, P. (2014). Athletes career development and transitions. In A.

579

G. Papaioannou \& D. Hackfort (Eds.), Routledge companion to sport and exercise psychology: Global perspectives and fundamental concepts. Routledge.

Stambulova, N. B., \& Wylleman, P. (2015). Special issue: Dual career development and transitions. Psychology of Sport and Exercise, 21, 1-134. Available at: https://www.sciencedirect.com/journal/psychology-of-sport-and-exercise/vol/21/suppl/C

Stambulova, N. B., \& Roy, S. (2019). Career transitions. In D. Hackfort \& R. J. Schinke (Eds.), The Routledge International encyclopaedia of sport and exercise psychology. Routledge.

Uphill, M., Sly, D., \& Swain, J. (2016). From mental health to mental wealth in athletes: Looking back and moving forward. Frontiers in Psychology, 7: 935. http://doi.org/10.3389/fpsyg.2016.00935

Van Slingerland, K., Durand-Bush, N., \& Rathwell, S. (2018). Levels and prevalence of mental health functioning in Canadian university student-athletes. Canadian Journal of Higher Education, 48(2), 149-168. https://doi.org/10.47678/cjhe.v48i2.188105

Wang, X., Hegde, S., Son, C., Keller, B., Smith, A., \& Sasangohar, F. (2020). Investigating menal health of US college students during the COVID-19 pandemic: Cross-sectional survey study. Journal of Medical Internet Research, 22(9), e22817. https://www.doi.org/10.2196/22817

World Health Organization (1999). WHOQOL annotated bibliography. Geneva, Switzerland: WHO Department of Mental Health. Retrieved from www.who.int/healthinfo/survey/whoqol-qualityoflife/en/

World Health Organization. (2004). Promoting mental health: Concepts, emerging evidence, practice. World Health Organization. 
601 Wylleman, P., Reints, A., \& De Knop, P. (2013). A developmental and holistic perspective on 602 athletic career development. In P. Sotiaradou, \& V. De Bosscher (Eds.), Managing high 603 performance sport (pp. 159-182). Routledge.

604

Zigmond, A. S., \& Snaith, R. P. (1983). The hospital anxiety and depression scale. Acta

605 Psychiatrica Scandinavica, 67(6), 361-370. https://doi.org/10.1111/j.1600-

606 0447.1983.tb09716

607 


\section{Tables}

\section{Table 1}

Sociodemographic Characteristics of Participants

\begin{tabular}{|c|c|c|}
\hline Characteristic & $\mathrm{n}$ & $\%$ \\
\hline \multicolumn{3}{|l|}{ Gender } \\
\hline Female & 34 & 34.3 \\
\hline Male & 65 & 65.7 \\
\hline \multicolumn{3}{|l|}{ Race } \\
\hline African American & 13 & 13.1 \\
\hline Caucasian & 77 & 77.8 \\
\hline Other & 9 & 9.1 \\
\hline \multicolumn{3}{|l|}{ Academic Standing } \\
\hline Freshman & 29 & 29.3 \\
\hline Sophomore & 21 & 21.2 \\
\hline Junior & 24 & 24.2 \\
\hline Senior & 18 & 18.2 \\
\hline Other & 7 & 7.1 \\
\hline \multicolumn{3}{|l|}{ Sport } \\
\hline Baseball & 1 & 1.0 \\
\hline Basketball & 4 & 4.0 \\
\hline Golf & 13 & 13.2 \\
\hline Lacrosse & 34 & 34.3 \\
\hline Rowing & 15 & 15.2 \\
\hline Soccer & 18 & 18.2 \\
\hline Volleyball & 14 & 14.1 \\
\hline \multicolumn{3}{|l|}{ Scholarship } \\
\hline Full & 14 & 14.1 \\
\hline Partial & 56 & 56.6 \\
\hline None & 29 & 29.3 \\
\hline \multicolumn{3}{|l|}{ Years Playing Sport } \\
\hline $0-3$ & 16 & 16.2 \\
\hline $4-7$ & 11 & 11.1 \\
\hline $8-10$ & 31 & 31.3 \\
\hline $10+$ & 41 & 41.4 \\
\hline
\end{tabular}

Note. $N=99$. Participants average age was 19.7 years old $(S D=1.5)$. 


\section{Table 2}

Descriptive Statistics for Continuous and Categorical Variables Used in Regression Analyses

\begin{tabular}{|c|c|c|c|c|c|c|c|c|c|c|c|c|}
\hline \multirow{2}{*}{$\frac{\text { Variables }}{\text { Continuous }}$} & \multicolumn{2}{|c|}{ Overall $(N=99)$} & \multicolumn{2}{|c|}{ Freshman $(n=29)$} & \multicolumn{2}{|c|}{ Sophomore $(n=21)$} & \multicolumn{2}{|c|}{ Junior $(n=24)$} & \multicolumn{2}{|c|}{$\underline{\text { Senior }(n=18)}$} & \multicolumn{2}{|c|}{ Other $(n=7)$} \\
\hline & $M$ & $S D$ & $M$ & $S D$ & $M$ & $S D$ & $M$ & $S D$ & $M$ & $S D$ & $M$ & $S D$ \\
\hline \multicolumn{13}{|l|}{ Well-Being } \\
\hline Total & 46.67 & 12.14 & 51.55 & 12.45 & 50.33 & 10.55 & 44.38 & 10.70 & 41.44 & 9.29 & 36.71 & 15.73 \\
\hline Subjective & 10.93 & 2.80 & 11.90 & 2.65 & 11.67 & 2.54 & 10.29 & 2.39 & 10.44 & 2.31 & 8.14 & 4.38 \\
\hline Psychological & 21.85 & 5.12 & 23.34 & 5.00 & 22.90 & 5.69 & 21.54 & 4.47 & 20.00 & 4.39 & 18.29 & 5.71 \\
\hline Social & 13.89 & 5.68 & 16.31 & 6.08 & 15.76 & 4.13 & 12.54 & 5.55 & 11.00 & 4.43 & 10.29 & 5.99 \\
\hline Worry & 52.85 & 13.76 & 56.31 & 12.31 & 51.33 & 12.57 & 50.75 & 16.23 & 51.83 & 15.06 & 52.86 & 10.84 \\
\hline Categorical & $N$ & $\%$ & $n$ & $\%$ & $n$ & $\%$ & $n$ & $\%$ & $n$ & $\%$ & $n$ & $\%$ \\
\hline \multicolumn{13}{|l|}{ Depression } \\
\hline Normal & 81 & 81.81 & 25 & 25.25 & 18 & 18.18 & 18 & 18.18 & 15 & 15.15 & 5 & 5.05 \\
\hline Subclinical & 21 & 21.21 & 5 & 5.05 & 7 & 7.07 & 3 & 3.03 & 4 & 4.04 & 2 & 2.02 \\
\hline Clinical & 36 & 36.36 & 13 & 13.13 & 5 & 5.05 & 8 & 8.08 & 8 & 8.08 & 2 & 3.03 \\
\hline \multicolumn{13}{|l|}{ Insomnia } \\
\hline No & 7 & 7.07 & 3 & 3.03 & 2 & 2.02 & 0 & 0.00 & 1 & 1.01 & 1 & 1.01 \\
\hline Yes & 92 & 92.92 & 26 & 26.26 & 19 & 19.19 & 21 & 21.21 & 17 & 17.17 & 6 & 6.06 \\
\hline \multicolumn{13}{|c|}{ Significant Insomnia ${ }^{\dagger}$} \\
\hline No & 17 & 17.17 & 7 & 7.07 & 4 & 4.04 & 2 & 2.02 & 3 & 3.03 & 1 & 1.01 \\
\hline Yes & 82 & 82.82 & 22 & 22.22 & 17 & 17.17 & 22 & 22.22 & 15 & 15.15 & 6 & 6.06 \\
\hline
\end{tabular}

Note. ${ }^{\dagger}$ An individual can be classified as having insomnia and significant insomnia. 
Table 3

Regression Results for Overall Well-Being and Quality of Life

\begin{tabular}{|c|c|c|c|c|c|c|c|c|c|c|}
\hline \multirow{3}{*}{ Variable } & \multicolumn{5}{|c|}{ Overall Well-Being } & \multicolumn{5}{|c|}{ Quality of Life } \\
\hline & \multirow[t]{2}{*}{$B$} & \multirow[t]{2}{*}{$S E$} & \multicolumn{2}{|c|}{$95 \%$ CI } & \multirow[t]{2}{*}{$p$} & \multirow[t]{2}{*}{$B$} & \multirow[t]{2}{*}{$S E$} & \multicolumn{2}{|c|}{$95 \%$ CI } & \multirow[t]{2}{*}{$p$} \\
\hline & & & $L L$ & $\mathrm{UL}$ & & & & LL & UL & \\
\hline COVID-19 & -0.83 & 0.47 & -1.76 & 0.10 & .08 & -0.90 & 0.86 & -2.62 & 0.82 & .29 \\
\hline \multicolumn{11}{|l|}{ Depression } \\
\hline Normal & \multicolumn{2}{|c|}{ Reference } & & & & & & & & \\
\hline Subclinical & -8.51 & 2.67 & -13.83 & -3.18 & .002 & -8.81 & 4.94 & -18.65 & 1.01 & .07 \\
\hline Clinical & -7.58 & 5.54 & -18.59 & 3.42 & .17 & -11.43 & 10.21 & -31.74 & 8.89 & .27 \\
\hline \multicolumn{11}{|l|}{ Anxiety } \\
\hline Normal & \multicolumn{2}{|c|}{ Reference } & & & & & & & & \\
\hline Subclinical & -7.26 & 2.50 & -12.24 & -2.29 & .004 & -13.32 & 4.61 & -22.50 & -4.14 & .005 \\
\hline Clinical & -12.36 & 3.00 & -18.34 & -6.38 & .001 & -18.61 & 5.55 & -29.65 & -7.59 & .001 \\
\hline Worry & 0.13 & 0.09 & -0.05 & 0.31 & .16 & 0.42 & 0.17 & 0.08 & 0.75 & .01 \\
\hline \multicolumn{11}{|l|}{ Insomnia } \\
\hline No & \multicolumn{2}{|c|}{ Reference } & & & & & & & & \\
\hline Yes & 2.44 & 4.41 & -6.32 & 11.20 & .58 & 10.87 & 8.13 & -5.29 & 27.03 & .18 \\
\hline \multicolumn{11}{|l|}{$\begin{array}{l}\text { Significant } \\
\text { Insomnia }\end{array}$} \\
\hline Insomnia & & & & & & & & & & \\
\hline No & \multicolumn{2}{|c|}{ Reference } & & & & & & & & \\
\hline Yes & -6.45 & 2.99 & -12.38 & -0.51 & .03 & -15.34 & 5.51 & -26.29 & -4.39 & .006 \\
\hline \multicolumn{11}{|l|}{ Academic } \\
\hline \multicolumn{11}{|l|}{ Standing } \\
\hline Freshman & \multicolumn{2}{|c|}{ Reference } & & & & & & & & \\
\hline Sophomore & -2.57 & 2.78 & -8.12 & 2.95 & .36 & -6.90 & 5.14 & -17.12 & 3.32 & .18 \\
\hline Junior & -7.73 & 3.71 & -15.10 & -0.35 & .04 & -16.88 & 6.85 & -30.50 & -3.27 & .02 \\
\hline Senior & -11.85 & 5.05 & -21.91 & -1.79 & .02 & -16.35 & 9.34 & -34.91 & 2.21 & .08 \\
\hline Other & -17.50 & 6.48 & -30.39 & -4.61 & .008 & -32.69 & 11.96 & -56.48 & -8.90 & .008 \\
\hline
\end{tabular}

Note. $\mathrm{R}$-squared ( $N=99)$ : Total Well-Being $=0.58$; Quality of Life $=0.45$. 


\section{Table 4}

Regression Results for the Subdimensions of Subjective Well-Being, Psychological Well-Being and Social Well-Being

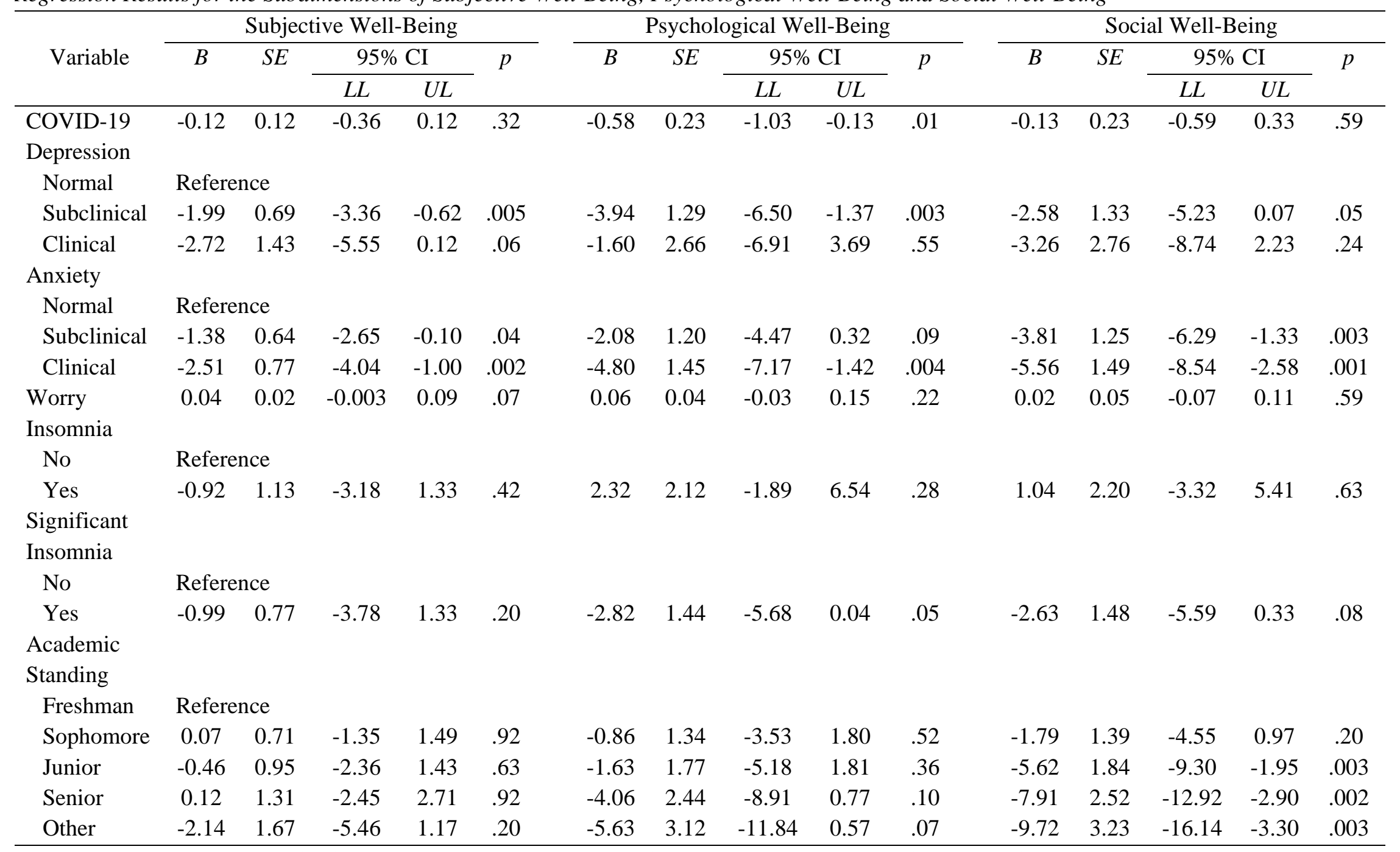

Note. R-squared ( $N=99)$ : Subjective Well-Being = 0.49; Psychological Well-Being = 0.47; Social Well-Being = 0.53. 